\title{
Paraptosis: mediation by MAP kinases and inhibition by AIP-1/Alix
}

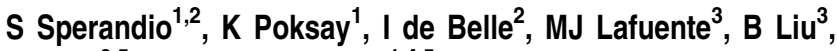 \\ $J$ Nasir $^{3,5}$ and DE Bredesen*,1,4,5 \\ 1 Buck Institute for Age Research, Novato, CA, USA \\ 2 The Burnham Institute, La Jolla, CA, USA \\ ${ }^{3}$ Section of Genetics and Informatics, Division of Genomic Medicine, University \\ of Sheffield Medical School, Sheffield, USA \\ ${ }^{4}$ Department of Neurology, University of California-San Francisco, San \\ Francisco, CA, USA \\ ${ }^{5}$ These two authors share senior authorship \\ * Corresponding author: D Bredesen, Buck Institute, 8001 Redwood Blvd., \\ Novato, CA 94945, USA. \\ E-mail: dbredesen@ buckinstitute.org
}

Received 4.11.03; revised 10.3.04; accepted 31.3.04; published online 11.6.04 Edited by Dr CJ Thiele

\begin{abstract}
Programmed cell death (pcd) may take the form of apoptotic or nonapoptotic pcd. Whereas cysteine aspartyl-specific proteases (caspases) mediate apoptosis, the mediators of nonapoptotic cell death programs are much less well characterized. Here, we report that paraptosis, an alternative, nonapoptotic cell death program that may be induced by the insulin-like growth factor I receptor (among other inducers), is mediated by mitogen-activated protein kinases (MAPKs) and inhibited by AIP-1/Alix. The inhibition by AIP-1/Alix is specific for paraptosis since apoptosis was not inhibited. Caspases were not activated in this paradigm, nor were caspase inhibitors effective in blocking cell death. However, insulinlike growth factor I receptor (IGFIR)-induced paraptosis was inhibited by MEK-2-specific inhibitors and by antisense oligonucleotides directed against $\mathrm{C}$-jun $\mathrm{N}$-terminal kinase-1 (JNK-1). These results suggest that IGFIR-induced paraptosis is mediated by MAPKs, and inhibited by AIP-1/Alix.

Cell Death and Differentiation (2004) 11, 1066-1075.

doi:10.1038/sj.cdd. 4401465

Published online 11 June 2004
\end{abstract}

Keywords: nonapoptotic programmed cell death; paraptosis; MAP kinase; AIP1/Alix

Abbreviations: IGFIR, insulin-like growth factor receptor; IGF-I, insulin-like growth factor I; LDH, lactate dehydrogenase; MAPK, mitogen-activated protein kinase; JNK, Jun N-terminal kinase

\section{Introduction}

Programmed cell death (pcd) is a form of cell death in which the cell plays an active role in its own demise. Although pcd has often been equated with apoptosis, it has become increasingly clear that nonapoptotic forms of pcd also exist. ${ }^{1-13}$ For example, certain developmental cell deaths, such as 'autophagic' cell death ${ }^{1-5}$ and 'cytoplasmic' cell death, ${ }^{2,4,6-9}$ do not resemble apoptosis. Furthermore, neurodegenerative diseases such as Huntington's disease and amyotrophic lateral sclerosis demonstrate neuronal cell death that does not fulfill the criteria for apoptosis. ${ }^{10,11}$ Ischemiainduced cell deaths may also display a nonapoptotic morphology, referred to as 'oncosis.' 13

The biochemical mechanisms underlying these alternative morphological forms of cell death remain incompletely defined. Understanding the mechanisms for these forms may potentially have implications for the understanding of evolutionary aspects of cell death programs, developmental cell death, neurodegeneration, and cancer therapeutics, and for the design of novel therapeutic agents for diseases featuring these alternative forms of cell death.

Cell death has been divided into two general types: pcd, in which the cell plays an active role; and passive (i.e., necrotic) cell death. The pcd observed during development and tissue homeostasis has been classified morphologically into three main types: type 1, nuclear or apoptotic; type 2, autophagic; and type 3 , cytoplasmic. $^{4}$

Apoptosis is the best characterized type of pcd: cells display membrane blebbing, loss of the asymmetry of phosphatidylserine (PS) in the plasma membrane,${ }^{14}$ nuclear fragmentation, and activation of caspases, the latter being a family of cell-suicide cysteine proteases. ${ }^{15,16}$ The biochemical activation of apoptosis occurs via two major pathways: the intrinsic pathway, initiated by the mitochondrial release of cytochrome $c$, resulting in the activation of caspase-9; and the extrinsic pathway, initiated by the activation of cell surface death receptors such as Fas, and resulting in the activation of caspase- 8 or $-10^{17}$ (a third general pathway, originating from the endoplasmic reticulum and resulting in the activation of caspase-12 and -9 , has also recently been described). ${ }^{18-22}$

Much less is known about the biochemical mediators of type 2 and type 3 cell death. Type 2 (autophagic) cell death can be activated in some cases by Ras, $^{23}$ while the molecular activation of type 3 cell death is unknown. Recently, the insulin-like growth factor I receptor (IGFIR) was shown to be capable of inducing an alternative, nonapoptotic form of pcd that is morphologically highly similar to type 3 . This form of pcd is characterized by cytoplasmic vacuolation, lack of apoptotic morphology, lack of caspase activation, lack of inhibition by caspase inhibitors (p35, zVAD.fmk, xiap, and Boc-aspartyl fmk) and $B c l-x_{L}$, and by a requirement for new gene transcription and translation. ${ }^{12}$ This nonapoptotic form of pcd was dubbed paraptosis. Subsequently, it was noted that the binding of the peptide neurotransmitter substance $P$ to its receptor, neurokinin-1 receptor, also induces a nonapoptotic form of pcd with similarities to paraptosis in its morphology, caspase independence, and requirement for gene transcription and translation. ${ }^{24} \mathrm{~A}$ striking similarity has been observed at the morphological level between paraptosis, type 3 (cytoplasmic) cell death, and the neuronal cell death observed in some neurodegeneration models, ${ }^{12}$ which suggests that 
paraptosis may be a physiologically relevant process. In order to assess its potential occurrence during development and in neurodegeneration, it will be necessary to identify specific markers for paraptosis, the latter of which are currently unavailable. It will also be important to characterize the molecular mechanisms underlying paraptosis, and ultimately to identify specific inhibitors for nonapoptotic programmed cell death. In the current report, we describe the mediation of IGFIR-induced paraptosis by the MAP kinase (MAPK) kinase MEK-2 and the MAP kinase JNK (Jun N-terminal kinase)-1, and describe the first specific inhibitor of paraptosis, AIP-1/ Alix. These results support the notion that multiple, distinct cell death programs may be employed by the cell (at least by mammalian cells), and that specific inhibitors for each may be identifiable.

\section{Results}

\section{Signaling through the IGFIR decreases survival}

We found previously that the expression in several mammalian cell lines of the membrane-targeted intracellular domain of IGFIR induces a nonapoptotic form of cell death, dubbed paraptosis. ${ }^{12}$ We also found that overexpression of the fulllength receptor was able to induce paraptosis.

To characterize the mechanism by which paraptosis is induced, we began by determining whether cell death induction was the result of a lack of trophic support in the presence of a death-inducing 'dependence receptor' (such as has been described for several receptors including $\mathrm{DCC},{ }^{25}$ $\mathrm{RET}^{26}$ the androgen receptor, ${ }^{27}$ and Unc5H2, ${ }^{28}$ among others), or the result of positive signaling via IGFIR. Therefore, we cloned the IGFIR cDNA into the episomal vector pCEP4, allowing the rapid selection for stable transformants containing autonomously replicating copies of the full-length IGFIR (to avoid discrepancies due to differential integration in the host genome), and counted the number of surviving colonies after 2 weeks of selection with or without insulin-like growth factor I (IGF-I). In five independent experiments, we found that when the IGFIR was stably expressed, treatment with IGF-I decreased the number of surviving colonies from two- to five-fold (Figure 1a, b).

Although these results were surprising at first because of the known antiapoptotic activity of IGF-I, similar results were obtained by substituting insulin at a supraphysiological concentration (where it is known to bind the IGFIR and mimic IGF-I effects) for IGF-I. Conversely, the use of an inactive analog of IGF-I capable of binding the receptor did not decrease colony numbers (Figure 1a, b). These results, in and of themselves, do not demonstrate cell death induction by IGFIR, but the observation of colony reduction is compatible with our earlier findings that IGFIR signaling may induce cell death. ${ }^{12}$

\section{Kinase activity of IGFIR is required for the induction of paraptosis}

In order to define the domain(s) within IGFIR responsible for the cell death signaling, we undertook a site-directed

a
\begin{tabular}{|c|c|c|c|c|}
\hline Experiment & $\begin{array}{c}\text { No } \\
\text { treatment }\end{array}$ & Insulin & IGF-I & $\begin{array}{c}\text { IGF-I } \\
\text { analog }\end{array}$ \\
\hline 1 & 591 & 268 & 309 & 642 \\
\hline 2 & 848 & 347 & 343 & 810 \\
\hline 3 & 1424 & 246 & 424 & 1480 \\
\hline 4 & 480 & 205 & 240 & 464 \\
\hline 5 & 400 & 128 & 128 & 404 \\
\hline
\end{tabular}

b

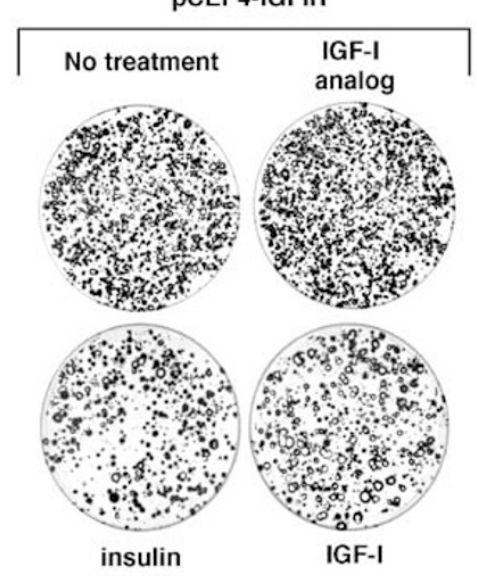

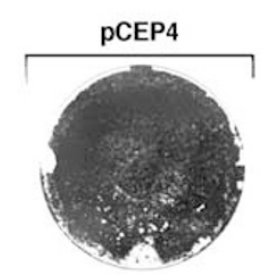

Figure 1 Signaling through the IGFIR decreases cell survival. (a) Colony-forming assay: number of surviving colonies of 293T cells following transfection with the episomal construct pCEP4-IGFIR, selection with Hygromycin B, and addition of the indicated drug for 2 weeks. Colonies were stained with Crystal violet. Results from five independent experiments are shown. Cutoff size for colony scoring was set at $2 \mathrm{~mm}$ diameter. A representative experiment is shown in (b). Note that the pCEP4 control colonies became confluent and therefore could not be counted accurately, but were estimated to be several-fold greater in number than those for the pCEP4IGFIR untreated group 
mutagenesis study. Since our previous studies have shown that expression of a myristylated IGFIR intracellular domain (IGFIR-IC) is sufficient for a strong paraptotic induction, we used this construct for this analysis. We first created a mutant of IGFIR-IC lacking kinase activity by mutating the lysine in the ATP-binding site at residue 1003 to an arginine (K1003R). This mutant-which was confirmed to be kinase inactive and did not display tyrosine autophosphorylation (Figure 2c)-was also unable to induce paraptosis, suggesting that the kinase activity of IGFIR may be involved in paraptosis, either directly or indirectly. To evaluate the role of IGFIR phosphorylation in cell death induction further, we created constructs of IGFIR-IC carrying mutations at residues known to be phosphorylation sites critical for the signal transduction of IGF-I through IGFIR. Phosphorylation at Tyr950 is required for the recruitment of IRS-1 and its subsequent recruitment of PI3K (which can also be recruited directly through phosphorylation at Tyr1316 29 and via the recruitment and phosphorylation of $\mathrm{Shc}^{30}$ ). Phosphorylation in the tyrosine cluster $1131 / 1135 / 1136$ is required for the kinase activity, since these residues are localized in the kinase active site. Other residues involved in signal transduction by IGFIR include tyrosines $1250 / 1251^{31}$ and the serine cluster at $1280-1283 .^{32}$

Figure $2 b$ and $d$ summarize the results of cell death assays obtained with these IGFIR-IC mutants, and show that the induction of paraptosis by IGFIR-IC requires an active kinase domain. Mutations such as K1003R and $\mathrm{Y} 1131 / 5 / 6 \mathrm{~F}$ that destroyed the kinase activity also lacked paraptosis activity, whereas the mutants lacking selected autophosphorylation sites including Y1250/1F, Y950/1316F, and the serine cluster mutation S1280/1/2/3A, but displaying an intact kinase activity, were still able to induce cell death. Immunoprecipitation assays followed by anti-phosphotyrosine immunoblots confirmed that all of the constructs displaying cell death activity were also able to autophosphorylate on tyrosine (Figure 2c). Interestingly, membrane localization was also required to induce paraptosis, as the IGFIR-IC nonmyristylated construct was able to autophosphorylate when expressed in 293T cells but did not induce cell death. The mutants of IGFIR-IC unable to induce cell death were also unable to reproduce the typical morphological changes observed in paraptosis, rounding of the cells and extensive cytoplasmic vacuolation (Figure $2 \mathrm{e}$ ).

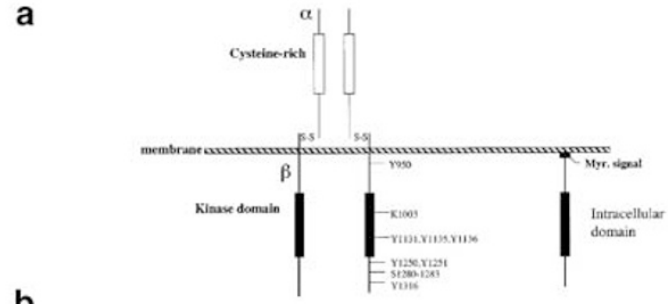

b

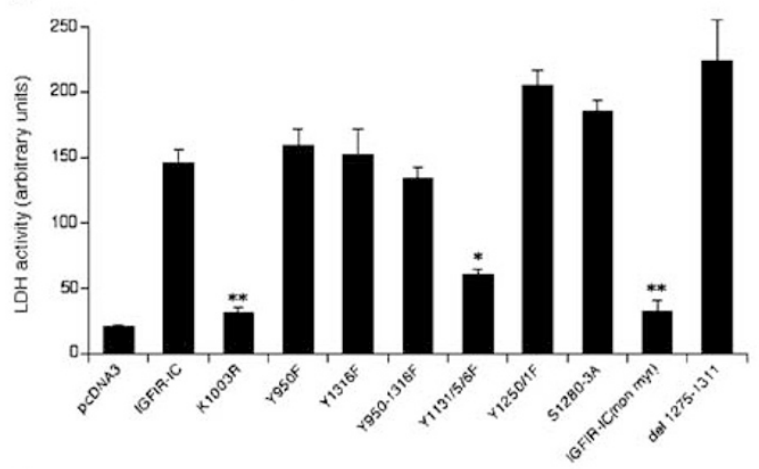

C

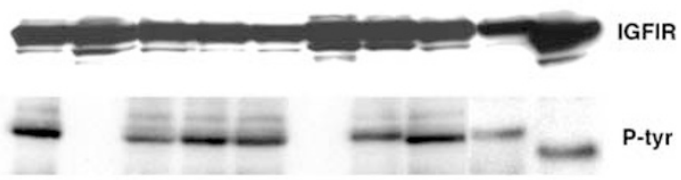

d
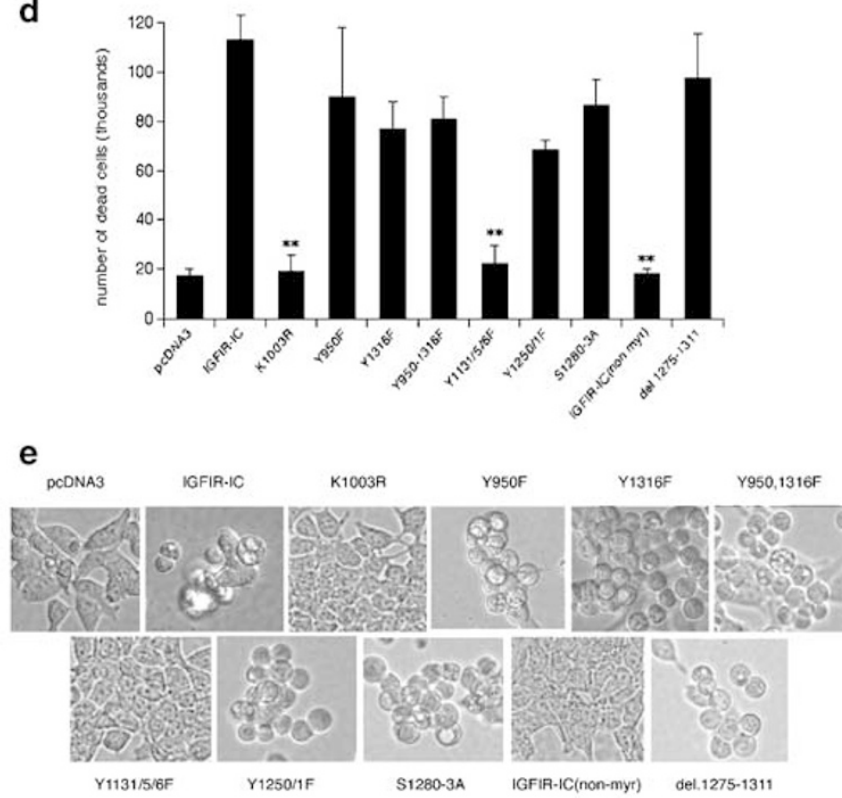

Figure 2 Induction of paraptosis by IGFIR correlates with its kinase activity. (a) Schematic representation of the IGFIR full-length and IC domain constructs. Residues targeted for point mutation are indicated. (b) LDH release cell death assay of 293T cells after transfection with IGFIR-IC, or the indicated mutant, shows that kinase activity correlates with cell death induction by IGFIR-IC. The error bars represent the S.E.M. from three independent experiments. One asterisk indicates a significant and two asterisks a highly significant difference from the IGFIR-IC sample as assessed by one-way ANOVA $(F=29.19, P<0.001$ for K1003R and nonmyristylated, $P<0.05$ for Y1131/5/6F, Bonferroni post hoc test). (c) Immunoblot with an antibody against the IGFIR $\beta$ subunit of cell lysates from the constructs used in (b), and shown in the same order, shows that all of the IGFIR-IC mutants were expressed at comparable levels (upper blot). The lower blot shows kinase activity as determined by $\alpha$ phosphotyrosine immunoblotting. (d) Cell death assay performed by counting floating trypan blue-positive cells gives consistent results with the LDH assay when comparing IGFIR-IC wild type or mutants. The error bars represent the S.E.M. from three independent experiments. Asterisks represent a highly significant difference from the IGFIR-IC sample as assessed by one-way ANOVA ( $F=6.543, P<0.01$, Bonferroni post hoc test). (e) Light microscopy images using Nomarsky optics of 293T cells transfected with the constructs used in (b) and (d). All of the IGFIR-IC constructs that induced cell death also induced the morphological changes consistent with paraptosis (rounding of the cells and cytoplasmic vacuolation) 


\section{Involvement of mitogen-activated protein kinase (MAPK) family members in paraptosis signaling}

Since paraptosis induction by IGFIR-IC was found to require receptor tyrosine kinase activity, we evaluated the previously described IGF signaling pathways for their potential involvement in the mediation of paraptosis. We found that both the ERK and JNK/SAPK pathways were engaged by IGFIR-IC expression in all of the constructs capable of inducing cell death, but not in those that lacked cell death activity (Figure 3). Another member of the MAPK family, the p38 MAPK, did not appear to be activated in paraptosis (data not shown). We then evaluated the potential contribution of these pathways to paraptosis signaling. As shown in Figure 4, downregulation of the stress-activated kinase JNK1, by means of antisense oligonucleotide transfection, reduced the cell death induced by IGFIR-IC partially but significantly (Figure 4a). Specific downregulation of JNK1 was confirmed by Western blot (Figure 4b).

A stronger inhibition of paraptosis was obtained using the specific inhibitor of MEK-1/2 activity, U0126 (Figure 5a), indicating that the MAPK, and to a lesser extent JNK/SAPK, pathways play an active role in the induction of paraptosis by the IGFIR-IC. While U0126 was effective in inhibiting paraptosis, we found that a similar inhibitor, PD98059, which shows relative specificity for MEK-1 over MEK-2, was almost completely ineffective, suggesting that MEK-2 rather than MEK-1 may mediate the signaling cascade that triggers paraptosis by IGFIR-IC.

Consistent with the cell death inhibition results, we found that U0126, but not PD98059, was able to prevent MAPK phosphorylation induced by IGFIR-IC expression (Figure $5 b$ ). To exclude the possibility of nonspecific kinase inhibition by UO126, we confirmed that, in the presence of this inhibitor, IGFIR-IC autophosphorylation was not affected (data not

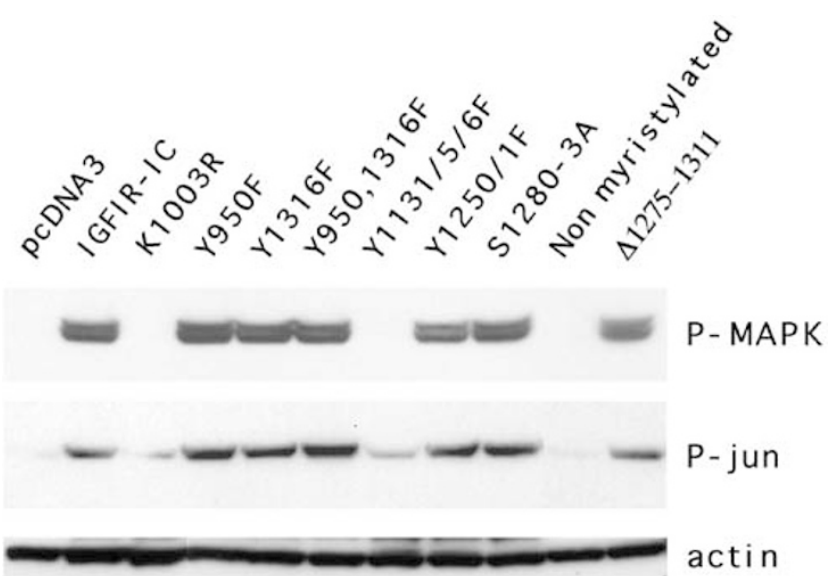

Figure 3 Activation of MAPK and JNK pathways by paraptosis-inducing IGFIRIC constructs. Western blot analysis of cell lysates from 293T cells transfected with IGFIR-IC or mutant constructs described in Figure 2. All of the IGFIR-IC mutants that induced cell death activated the MAPK pathway (as assessed by $\alpha$ phospho-MAPK Western (upper blot)) and the JNK pathway (as measured by phosphorylation of $\mathrm{c}$-jun (middle blot)). Note that the nonmyristylated form of IGFIR-IC displayed tyrosine phosphorylation but did not induce MAPK or c-jun phosphorylation, and did not induce cell death. At the bottom, an immunoblot performed using an anti-actin antibody is shown to verify equal loading

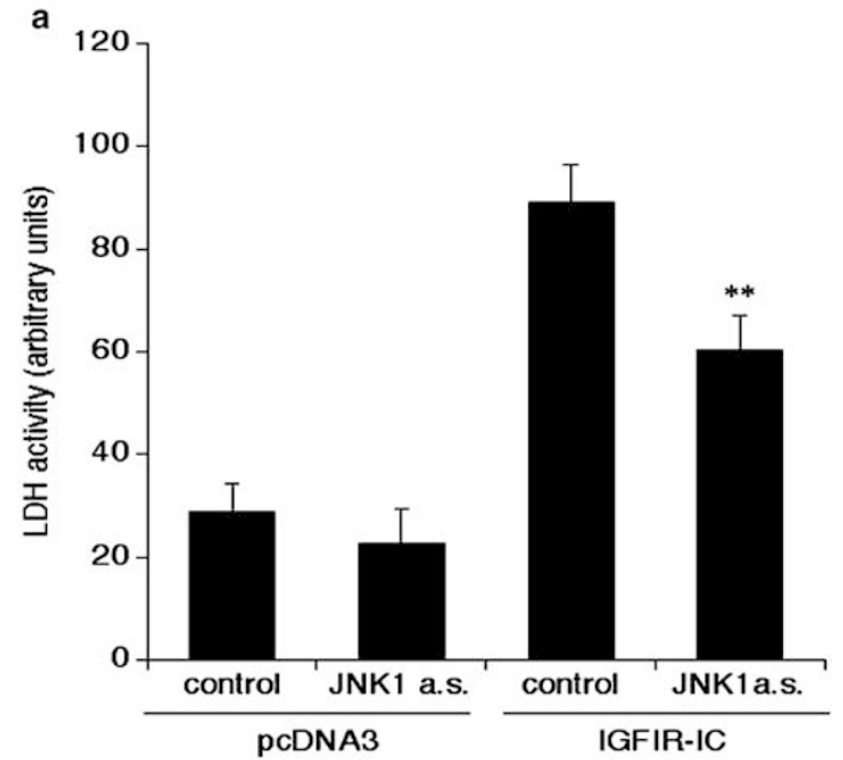

b

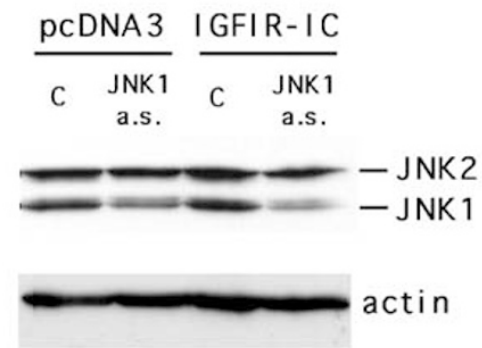

Figure 4 Antisense inhibition of JNK-1 reduces paraptosis induced by IGFIRIC. (a) LDH release cell death assay of 293T cells transfected with IGFIR-IC. Cell death was partially but significantly decreased by antisense inhibition of JNK-1 following cotransfection with specific antisense oligonucleotides for JNK1, but not by a scrambled control oligonucleotide. The error bars represent the S.E.M. from four independent experiments. The asterisks indicates a highly significant difference from the IGFIR-IC/scrambled oligo control sample as assessed by twotailed $t$-test $(P<0.0004)$. (b) Anti-JNK1/2 immunoblots showing downregulation of JNK-1 (upper blot) in 293T cells transfected with antisense oligonucleotides, in comparison to the control scrambled oligonucleotide. Equal loading was verified by anti-actin immunoblotting (lower blot)

shown). Treatment with UO126 was also effective in reducing the cell death as well as MAPK phosphorylation induced by transfection of the full-length IGFIR in combination with IGF-I, ruling out the possibility that this result was only restricted to the expression of the IC domain of the receptor (Figure $5 c, d$ ) Furthermore, UO126 did not affect IGFIR-driven JNK activation, since $c$-jun phosphorylation induced by IGFIR-IC was not altered in the treated sample (Figure $5 \mathrm{~b}$ ). A minor reduction of cell death was observed when 293T cells transfected with IGFIR-IC were treated with the general JNK inhibitor SP600125. However, only a slight reduction of JNK activity, as measured by c-jun phosphorylation, was observed following treatment of cells with SP600125, indicating that this inhibitor was relatively ineffective under the conditions used. We also tested the specific inhibitor for PI3K, Wortmannin, but did not observe any reduction of paraptosis induced by IGFIRIC (Figure 5a, b), indicating that PI3K activation is not required 


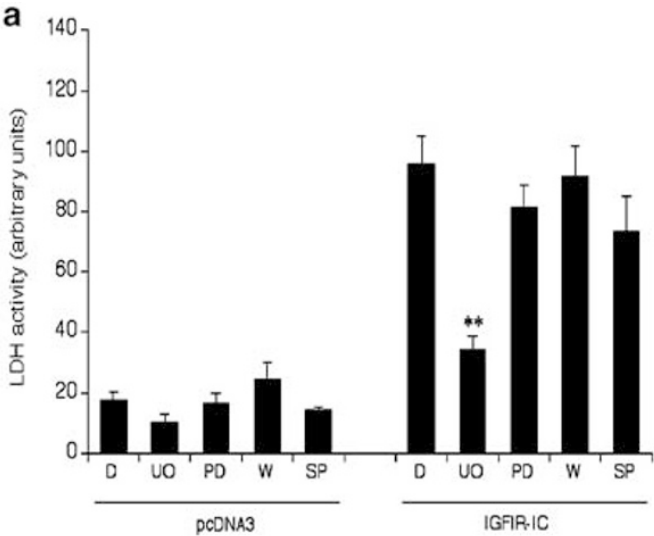

b

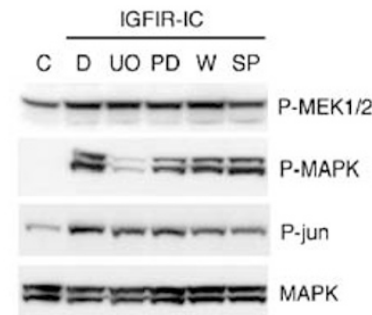

C

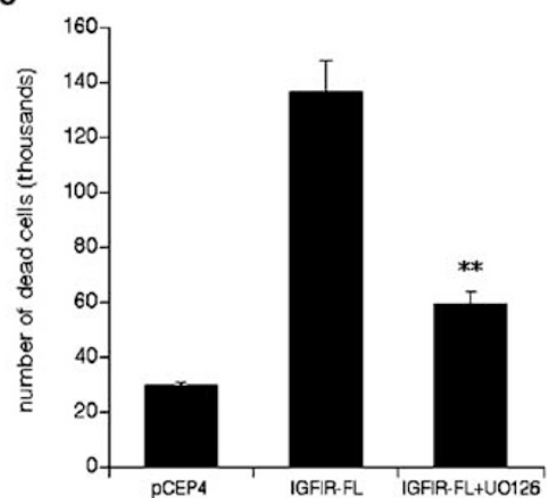

d

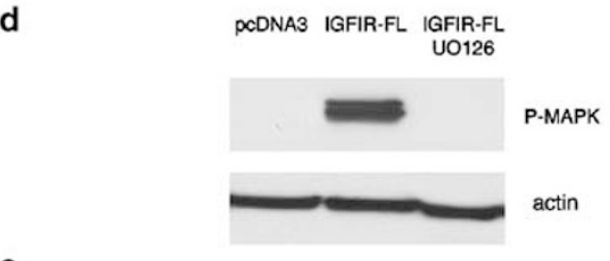

e
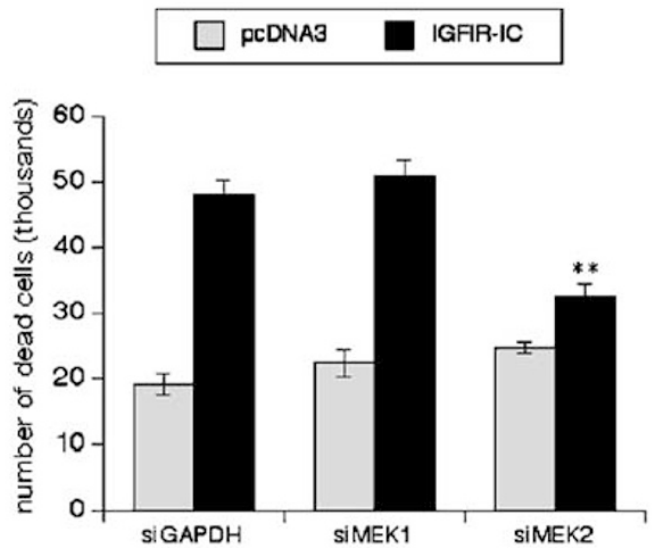

f

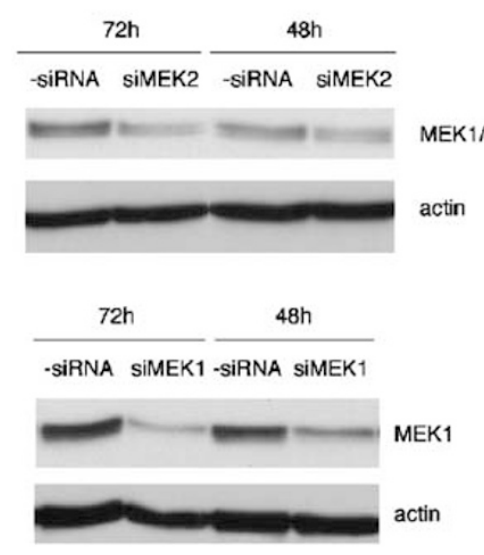

Figure 5 Blocking the MAPK pathway inhibits paraptosis induced by IGFIR. Cell death (a) and Western blot analysis (b) of 293T cells transfected with IGFIR-IC and treated with various kinase inhibitors. Inhibition of MEK1/2 by U0126 prevented cell death measured by LDH release, as well as blocking the activation of MAPK (as detected by $\alpha$-phospho-MAPK Western), whereas it did not affect MEK1/2 phosphorylation. The JNK inhibitor SP600125 demonstrated only a modest effect on both cell death and on c-jun phosphorylation. $\mathrm{C}=$ control transfection (pcDNA3) with the addition of: vehicle $\mathrm{DMSO}, \mathrm{D}=\mathrm{DMSO}$ at $0.2 \%, \mathrm{UO}=\mathrm{UO} 126$ at $20 \mu \mathrm{M}, \mathrm{PD}=\mathrm{PD} 98059$ at $20 \mu \mathrm{M}, \mathrm{W}=$ Wortmannin at $200 \mathrm{nM}, \mathrm{SP}=\mathrm{SP} 600125$ at $10 \mu \mathrm{M}$. Total cell lysate $(50 \mu \mathrm{g})$ was analyzed for each antibody. The $\alpha$-MAPK Western demonstrates that the use of the kinase-specific inhibitors did not affect the total amount of each protein. The error bars represent the S.E.M. from five independent experiments. Asterisks indicate a highly significant difference from the IGFIR-IC/DMSO-treated control sample as assessed by one-way ANOVA $(F=28.53$, $P<0.001$, Bonferroni post hoc test). (c) Cell death assay by trypan blue-positive cell counts. 293T cells were transfected with the full-length IGFIR alone or together with the MEK inhibitor UO126. The error bars represent the S.E.M. from three independent experiments. Asterisks indicate a significant difference from the IGFIR-FL sample $(P<0.015$, as determined by two-tailed $t$-test). (d) Western blot using a phospho-MAPK antibody of samples shown in (c) showing downregulation of the induced activation of MAPK. The same blot was reprobed with an anti-actin antibody. (e) RNA interference experiment using either GAPDH (control), MEK-1-, or MEK-2-specific siRNA. The siRNAs were transfected into 293T cells, and 48-72 $\mathrm{h}$ later either control (pcDNA3) or IGFIR were transfected into the same cells. Cell death was assessed trypan blue exclusion. The error bars represent the S.E.M. from five independent experiments. The asterisks indicate a highly significant difference from the IGFIR-IC/siGAPDH sample as assessed by two-tailed $t$-test $(P<0.0012)$. (f) The downregulation of MEK-1 and MEK-2 using the specific siRNA was demonstrated by Western blotting. The same blots were reprobed with an anti-actin antibody

for paraptosis, a finding consistent with the mutagenesis analysis described above.

In order to confirm a role for MEK-2 in paraptosis induction, we performed RNA interference experiments using specific SiRNA for MEK-1 or MEK-2. We found that downregulation of MEK-2, but not MEK-1, by RNAi significantly decreased paraptosis induced by IGFIR-IC compared to samples transfected with a control siRNA for GAPDH (Figure 5e). The downregulation of either MEK-1 or MEK-2 in these conditions was confirmed by Western blotting (Figure 5f).

Taken together, these results suggest that MAP kinase (and kinase kinase) family members, in particular MEK-2 and to a lesser extent JNK1, may function as mediators of paraptosis. 


\section{A new function for the ALG-2-interacting protein AIP1/Alix as an inhibitor of paraptosis}

The protein AIP1/Alix was identified independently by two groups as a protein interacting with the cell death-related calcium-binding protein ALG-2. ${ }^{33,34}$ Although the roles of ALG-2 and of AIP1/Alix in programmed cell death remain incompletely defined, ${ }^{33}$ the yeast AIP1 homologue BRO1 has been genetically and functionally linked to the Pkc1p-MAPK cascade. Mutations in BRO1 result in a phenotype similar to that associated with mutations in BCK1, the latter of which is a MAPK that mediates cell integrity. ${ }^{35}$ Given the findings described above suggesting that paraptosis is mediated by MAPK activation, we evaluated the effects of AIP1/Alix on both apoptotic and paraptotic cell death. Whereas AIP1/Alix inhibited paraptosis induced by both IGFIR-IC and IGFIR full length (Figure 6a-f) as determined by biochemical and morphological criteria, it did not inhibit apoptosis (Figure 6g). Consistent with this result, we found that the overexpression of AIP1/Alix reduced both JNK and MAPK activation by IGFIR, indicating that the mechanism of protection from cell death may involve interference with the triggering of these two signaling pathways (Figure $6 \mathrm{~b}, \mathrm{f}$ ). Together with the inhibition of cell death and the downregulation of IGFIR signaling, AIP1/ Alix was able to prevent the paraptotic morphology induced by IGFIR (Figure 6d).

Although the function of AIP1/Alix is not yet known, homologous proteins in both yeast and fungi appear to function in a response pathway to cellular stress, including alkaline and osmotic stress. ${ }^{35,36}$ Our results are consistent with and complement these results, suggesting a novel function for AIP1/Alix as an inhibitor of paraptosis.

To understand the involvement of AIP1/Alix in paraptosis further, we asked at which specific step AIP1/Alix affected the signaling cascade from the IGFIR. Although we could not detect a direct interaction between IGFIR and AIP1/Alix in cotransfection and coimmunoprecipitation assays (data not shown), we found that AIP1/Alix coexpression potently decreased the extent of tyrosine phosphorylation on IGFIR (Figure 6c). a

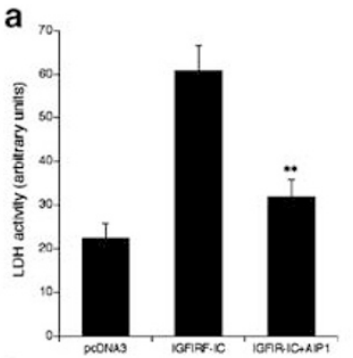

b

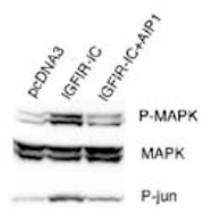

C

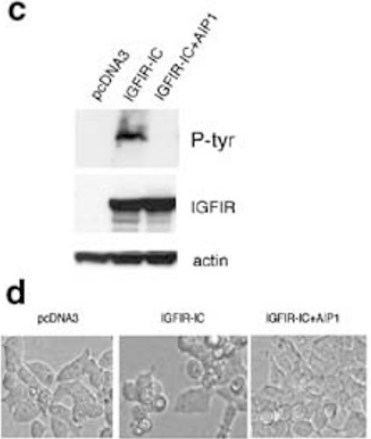

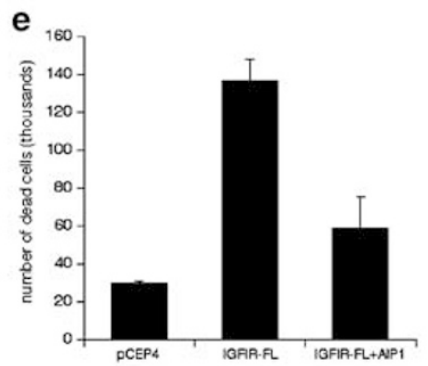

f

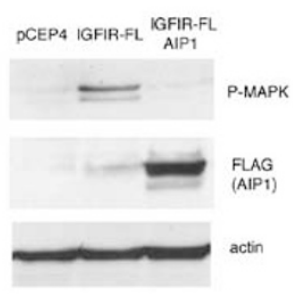

g

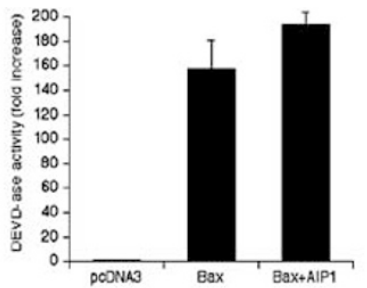

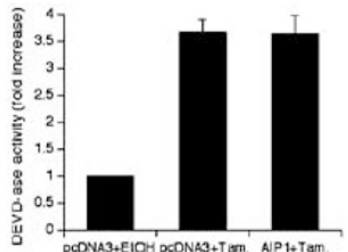

Figure 6 AIP1/Alix inhibits paraptosis induced by IGFIR, and downregulates IGFIR signaling, but does not inhibit apoptosis. (a) Cell death assay, measuring LDH release, following cotransfection into 293T cells of IGFIR-IC with AIP1/Alix. Cotransfection of AIP1/Alix inhibited both cell death and MAPK and c-jun phosphorylation induced by IGFIR transfection (the latter as assessed by Western blot analysis of phosphoproteins). The error bars represent the S.E.M. from eight independent experiments. The asterisks indicate a highly significant difference from the IGFIR-IC alone sample as assessed by two-tailed $t$-test $(P<0.0002)$. (b) Although phosphorylation was affected by AIP1/Alix, protein concentration was not affected, as demonstrated by the $\alpha$-MAPK and $\alpha$-jun Western analyses. (c) Western blot using an anti-phospho-tyrosine antibody on IGFIR-IC immunoprecipitation samples following transfection of IGFIR-IC alone or in combination with AIP1/Alix (top blot). The middle and lower blots show the whole cell lysates from the same experiment probed with anti-IGFIR $\beta$ subunit and anti-actin antibodies, respectively. (d) Light microscopy images of 293T cells transfected with IGFIR-IC alone or in the presence of AIP1 demonstrate that AIP1 inhibits the paraptotic morphology consistent with the cell death inhibition and downregulation of IGFIR signaling. (e) Trypan blue cell counts of 293T cells transfected with IGFIR full-length alone or in combination with AIP1. (f) Western blot of cell lysates from the experiment shown in (e) using anti-phospho-MAPK antibodies. The same blot was reprobed with anti-FLAG antibody to demonstrate AIP1 expression and with anti-actin antibody as a loading control. (g) Apoptosis assay measuring Ac-DEVD-AFC cleaving activity of 293T cells transfected with Bax alone or in combination with AIP1, and 293T cells treated with Tamoxifen with or without previous transfection with AIP1 


\section{Discussion}

We reported previously that the expression of IGFIR induces a form of nonapoptotic pcd dubbed paraptosis, which is morphologically similar to developmental cell death (type 3), excitotoxic cell death, and cell death in several other paradigms. ${ }^{12}$ While the assessment of the frequency of paraptosis in physiologically relevant contexts awaits the identification of specific markers, the current report addresses the molecular mechanism of paraptosis induction by IGFIR. We have shown that paraptosis requires the receptor kinase activity, based on mutagenesis studies. Consistent with these results, constitutive signaling through the receptor by IGF-I, or insulin at supraphysiological concentrations, decreased cell survival.

Although IGFIR is known primarily for its role in cell growth and development and for its transforming and antiapoptotic signaling, it also induces differentiation of a variety of cell types. Recently, our group, as well as others, have established a new role for IGFIR in cell death induction. ${ }^{12,37}$ In keeping with this emerging role, a potential function of IGFIR as a tumor suppressor was suggested by findings that the expression of IGFIR was decreased in prostate cancer, ${ }^{38}$ and its reexpression in immortalized human prostate cells inhibited the malignant phenotype. ${ }^{39}$ A potential role for IGFIR in developmental cell death could explain part of the phenotype of IGFIR-null mice, in which a higher neuronal density in the brainstem and spinal cord was observed. ${ }^{40}$

Engagement of at least two signaling pathways triggered by IGFIR, the MAPK/ERK and JNK pathways, occurred in paraptosis. Both pharmacological inhibition of MAPK and downregulation of MEK-2 by RNAi, as well as downregulation of JNK1 by antisense oligo transfection, inhibited paraptosis. Involvement of MAPK in paraptosis is somewhat surprising since this pathway has typically been associated with cell survival or proliferation rather than cell death. ${ }^{41}$ However, other groups have demonstrated that the activation of ERKs is necessary for cell death in different paradigms, such as neuronal cell death induced by glutamate, ${ }^{42}$ okadaic acid, ${ }^{43}$ hemin, ${ }^{44}$ genistein, ${ }^{45}$ and 6 -hydroxydopamine. ${ }^{46}$ In addition, another activator of the MAPK pathway, Ras, has been implicated previously in caspase-independent pcd. ${ }^{23}$ Further work will be required to characterize the upstream activators and the downstream targets of MAPK involved in nonapoptotic pcd, and to discern the MAPK-dependent signals that distinguish a trophic response from a pcd response.

We found previously that a dominant-negative mutant (catalytic mutant) of caspase- 9 inhibited paraptosis, and, in complementary studies, that procaspase- 9 expression led to both apoptosis and paraptosis. Interestingly, a recent report showed that caspase- 9 is a direct target of MAPK, and that phosphorylation at Thr125 by ERK-2 inhibits the proapoptotic activity of caspase-9. ${ }^{47}$ Although it remains unclear at which critical step caspase- 9 effects paraptosis, one could speculate that modification of caspase- 9 by phosphorylation might function as a switch from a proapoptotic activity to a proparaptotic activity of the protease.

The finding of JNK-mediated nonapoptotic pcd for IGFR-IC is worthy of comment given that JNK activation has been implicated in numerous apoptotic paradigms. ${ }^{41,48}$ The current results argue that JNK-1 may also mediate nonapoptotic pcd (at least in combination with MAPK), and support the earlier contention that there is crosstalk between apoptotic and nonapoptotic pcd. ${ }^{12}$

Whether signals transduced by trophic factor receptors such as IGFIR lead to cell survival, proliferation, and differentiation, or lead to cell death induction, may depend on quantitative effects - that is, hyperstimulation that exceeds some threshold may induce cell death (reminiscent of neuronal excitotoxicity, which also may induce nonapoptotic cell death ${ }^{49}$ ) - or qualitative effects such as cell state, costimulatory signals, etc. (or both quantitative and qualitative effects).

One implication of the current results is that paraptosis and apoptosis may be complementary cell death programs: for example, withdrawal of a trophic factor such as IGF-I may lead to apoptosis, whereas hyperactivation of a trophic factor receptor such as IGFIR inactivates cellular apoptotic pathways, but may induce the alternative cell death program of paraptosis. Such 'trophotoxicity' - that is, toxicity resulting from activation of a trophic factor receptor - may be involved with cell death preventing autocrine loop-induced neoplasia. A corollary to this notion is that autocrine loop tumors would be predicted to feature mutations in paraptosis-mediating genes.

Finally, we report here the identification of AIP1/Alix as the first endogenous inhibitor of paraptosis. Although the function of AIP1/Alix is still incompletely defined, it has been proposed that it might cooperate with its interacting protein ALG-2 in promoting apoptosis. ${ }^{33}$ Functional and genetic evidence have linked the yeast homologue of AIP1/Alix, BRO1, to components of the MAPK signaling pathway, and to response to cellular stress. This evidence is in agreement with a potential role for AIP1/Alix in regulating paraptosis. Interestingly, it was recently shown that overexpression of the C-terminal half of AIP1/Alix (a region that inhibits apoptosis) induces the formation of vacuoles, possibly through its interaction with endophilins. ${ }^{50}$ Taken together, these results are compatible with a model in which the full-length AIP1/Alix facilitates apoptosis but inhibits both paraptosis and paraptosis-dependent cytoplasmic vacuolation, whereas its C-terminally deleted form acts as a dominant negative by preventing apoptosis and inducing vacuolation.

Although further work will be necessary to clarify its specific mode of action, the current report complements previous studies in the characterization of AIP1/Alix as a multifunctional protein important in signal transduction and ultimately cell integrity.

\section{Materials and Methods}

\section{Reagents}

IGFI, insulin, and the PI3K-specific inhibitor Wortmannin were obtained from SIGMA (St. Louis, MO, USA). IGF-I analog was obtained from Bachem (Torrance, CA, USA). Hygromycin B was obtained from Roche (Basel, Switzerland). The specific inhibitors PD98059, U0126 for MEK-1/ 2, and SP600125 for JNK were obtained form Calbiochem (La Jolla, CA, USA), and were used as indicated. 


\section{Antibodies}

HRP-conjugated anti-phosphotyrosine antibody was obtained form Transduction Laboratories (BD Bioscience, San Diego, CA, USA) and used at 1:4000 dilution for Western blot analysis. Anti-phospho-MAPK, anti-phospho-jun (Ser 63), anti-phospho-MEK, anti-MAPK, anti-jun, and anti-MEK1-2 antibodies were obtained from Cell Signaling (Beverly, MA, USA) and used at 1:1000 dilution for Western blots. The anti-JNK1/2 antibody was obtained from Pharmingen (BD Bioscience, San Diego, CA USA), and used at $1: 1000$ dilution. The anti-MEK1 antibody was obtained from StressGen. The anti-IGFIR $\beta$ subunit and anti-actin antibodies were obtained from SIGMA (St. Louis, MO, USA) and used, respectively, at $1: 200$ and at $1: 1000$ dilution for Western blot. Anti-IGFIR antibody $(1 \mu \mathrm{g})$ was used in the immunoprecipitation assays.

\section{Cell culture}

Human embryonic kidney 293T cells were grown in high glucose DMEM (Life Technologies, Grand Island, NY, USA) supplemented with $10 \%$ fetal bovine serum (SIGMA, St. Louis, MO, USA) and penicillin/streptomycin $100 \mathrm{U} / \mathrm{ml}$ (Life Technologies, Grand Island, NY, USA). The cultures were incubated at $37^{\circ} \mathrm{C}$ in $95 \%$ air $5 \%$ carbon dioxide with $95 \%$ humidity.

\section{Establishment of stable transfectants}

For the colony-forming assay, $1 \times 10^{6}$ cells were seeded in $6 \mathrm{~cm}$ plates the day before transfection. The cells were then transfected using $2 \mu \mathrm{g}$ of either control vector PCEP4 or PCEP4-IGFIR with $10 \mu$ l of Lipofectamine 2000 (Invitrogen, Carlsbad, CA, USA). The day after transfection, the cells were passaged into new plates, and the selection was started using $200 \mu \mathrm{g} / \mathrm{ml}$ of Hygromycin B; $1 / 5$ of each plate was seeded into each $10 \mathrm{~cm}$ dish. For the pCEP4-IGFIR sample, four plates were made for different treatments. One plate of untransfected cells was split in parallel to monitor that complete selection had occurred. The cells were cultured under selection for 2 weeks at which time single-cell clones of a visible size had formed. The cells were washed with PBS and fixed in 4\% formaldehyde for $10 \mathrm{~min}$, rinsed several times with water and stained with a solution of $0.1 \%$ crystal violet. Colonies of $2 \mathrm{~mm}$ or larger were counted.

\section{Constructs}

IGFIR-IC mutants were constructed by the QuikChange method (Stratagene, La Jolla, CA, USA) following the protocol suggested by the manufacturer.

\section{Transfections}

Transfections of IGFIR-IC wild-type and mutants were performed using Lipofectamine 2000 (Invitrogen, Carlsbad, CA, USA) following the manufacturer's instructions. Briefly, $0.5 \times 10^{6}$ cells were seeded in sixwell plates the day before transfection. DNA $(1 \mu \mathrm{g})$ was complexed with $5 \mu \mathrm{l}$ of Lipofectamine 2000 and administered to the cells for $24 \mathrm{~h}$ at which time the culture medium was replaced. The rate of cell death was assessed as follows: $100 \mu$ l of culture medium was collected $48 \mathrm{~h}$ after the beginning of transfection and used to perform LDH assays. For the AIP1 inhibition studies, $2 \mu \mathrm{g}$ of total DNA consisting of $0.5 \mu \mathrm{g}$ of IGFIR construct $+1.5 \mu \mathrm{g}$ of DNA for either AIP1 or control pcDNA3, and $10 \mu \mathrm{l}$ of Lipofectamine 2000 were used.

\section{JNK-1 antisense experiments}

The oligonucleotide sequences used were: ctctctgtaggcccgcttgg for human JNK-1, and tcgcatcgaccogcccacta for the control scrambled oligonucleotide. The oligonucleotides were transfected using Lipofectamine 2000 (3.2 $\mu$ l of lipofectamine/100 ng oligonucleotide) at an oligonucleotide concentration of $100 \mathrm{nM} 24 \mathrm{~h}$ prior to IGRIR-IC transfection.

\section{RNA interference experiments}

Target validated siRNA for GAPDH, MEK-1, and MEK-2 were obtained from Ambion and transfected into cells by means of the reagent siPORT Amine (Ambion, Austin, Tx, USA), following the manufacturer's instructions. Briefly, 293T cells were seeded into 12-well plates at $1.5 \times 10^{5}$ cells/well the day before transfection. siRNAs were used at 10$20 \mathrm{nM}$ for GAPDH, 5-10 nM for MEK-1, and 10-20 nM for MEK-2. The medium was replaced the day after transfection with fresh culture medium containing $20 \mu \mathrm{M}$ of the caspase inhibitor T-butyloxycarbonyl-Asp $(0$ methyl)-flouromethyl ketone (BAF) (Enzyme System Products, Livermore, CA, USA) to prevent apoptosis due to downregulation of MEKs. At 48$72 \mathrm{~h}$ following siRNAs transfection, the cells were subsequently transfected with either pcDNA3 (control vector) or IGFIR-IC construct. At $48 \mathrm{~h}$ after this transfection, the cell death was assessed by trypan blue exclusion as described below.

\section{LDH assay}

The LDH cell death assay was based on the method of Koh and Choi, ${ }^{51}$ with some modifications. The relative rate of lactate dehydrogenase (LDH) released by the dead cells in the culture medium was determined as a function of the disappearance of NADH in the reaction:

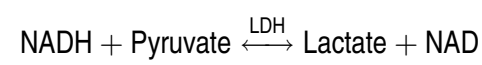

Briefly, $100 \mu \mathrm{l}$ of culture medium of each sample are collected $48 \mathrm{~h}$ after transfection and plated in a 96-well plate. $\beta$-NADH (reduced form) $(5 \mathrm{mg}$ ) are dissolved in $20 \mathrm{ml}$ of PBS with the addition of $0.5 \mathrm{ml}$ of $100 \mathrm{mM}$ sodium pyruvate, and $100 \mu \mathrm{l}$ of this solution is added to the medium in the plate. The $V_{\text {MAX }}$ of disappearance of NADH is determined by subsequent photometric reading every $11 \mathrm{~s}$ within $2 \mathrm{~min}$ and $30 \mathrm{~s}$ after the addition of the NADH/Pyruvate solution. The relative rate of cell death in each sample is expressed in arbitrary units of the $V_{\text {MAX. }}$.

\section{Assessment of cell death by trypan blue exclusion}

Cell death was assessed as described earlier. ${ }^{12}$ Typically, $48 \mathrm{~h}$ after transfection, the floating cells were collected from the culture medium by centrifugation for $6 \mathrm{~min}$ at $6000 \mathrm{rpm}$ in a tabletop centrifuge. The cell pellet was resuspended in $100 \mu \mathrm{l}$ of PBS to which $100 \mu$ of trypan blue was added. Dead cells were counted by four independent hemacytometer counts.

\section{Assessment of apoptosis}

The rate of apoptosis was assessed by measuring Ac-DEVD-AFC cleaving activity in cell lysates. Briefly, 293T were seeded at $1 \times 10^{6} \mathrm{cell} /$ plate into $6 \mathrm{~cm}$ plates the day before transfection. For Bax-induced cell death, the cells were transfected with either Bax alone or in combination with AIP1, at the ratio 1:3. For the Tamoxifen treatment, the cells were transfected with either control DNA (pcDNA3) or the AIP1 construct and treated with Tamoxifen at $50 \mu \mathrm{M}$ the day after transfection. Cell lysates were obtained by resuspending cell pellet in NP40 lysis buffer $(50 \mathrm{mM}$ 
Hepes pH 7.6, $250 \mathrm{mM} \mathrm{NaCl}, 2 \mathrm{mM}$ EDTA, 0.1\% NP40). Cell lysates $(100 \mu \mathrm{g})$ were incubated in caspase buffer $(10 \mathrm{mM}$ PIPES, $0.1 \mathrm{mM} \mathrm{NaCl}$, $0.1 \mathrm{mM}$ EDTA, $10 \mathrm{mM} \mathrm{DTT}, 10 \%$ sucrose, $0.1 \%$ CHAPS at pH 7.4), in the presence of $100 \mu \mathrm{M}$ caspase substrate. Hydrolysis of Ac-DEVD-AFC was followed on a Molecular Devices fmax plate reader at $37^{\circ} \mathrm{C}$.

\section{Western blot analysis}

Total cell extracts were obtained by collecting the cells $24 \mathrm{~h}$ after transfection and lysing the cell pellets in RIPA buffer $(50 \mathrm{mM}$ Tris- $\mathrm{HCl}, \mathrm{pH}$ $8,150 \mathrm{mM} \mathrm{NaCl}, 1 \% \mathrm{NP} 40,0.5 \%$ Deoxycholate, $0.1 \%$ SDS) or NP40 lysis buffer supplemented with Complete protease inhibitors (Roche, Basel, Switzerland) and phosphatase inhibitors $\mathrm{Na}_{3} \mathrm{VO}_{4}(2 \mathrm{mM}), \mathrm{NaF}(20 \mathrm{mM})$ for phosphoprotein studies. Equal amounts of supernatants after $14000 \mathrm{rpm}$ spins for $10 \mathrm{~min}$ were run on $4-12 \%$ Bis-Tris NuPage gels (Invitrogen, Carlsbad, CA) and transferred onto a PVDF membrane (Millipore, Billerica, MA, USA). Western blot analysis was performed as suggested by each antibody's supplier and, after incubation with species-specific HRPconjugated secondary antibody, the specific protein bands were detected by chemiluminescence with the ECL reagents (Amersham, Arlington Heights, IL, USA). Immunoprecipitation of the IGFIR was performed by lysing cells in NP40 lysis buffer, supplemented with Complete protease inhibitors and phosphatase inhibitors $\mathrm{Na}_{3} \mathrm{VO}_{4}(2 \mathrm{mM}), \mathrm{NaF}(20 \mathrm{mM})$. Supernatants $(400 \mu \mathrm{g})$ after $14000 \mathrm{rpm}$ spin for $10 \mathrm{~min}$ were incubated with $1.5 \mu \mathrm{g}$ of anti-IGFIR antibody overnight at $4^{\circ} \mathrm{C}$, and subsequently with Immunopure Immobilized Protein A (Pierce, Rockford, IL, USA). Following four washes in lysis buffer, the beads were boiled in loading buffer and the immunoprecipitates run on $4-12 \%$ NuPage gels (Invitrogen, Carlsbad, CA, USA) and analyzed by Western blot.

\section{Acknowledgements}

We thank $D$ Mercola for the JNK antisense oligonucleotides and $G$ Salvesen for the helpful discussions and for serving as mentor to SS. This work was supported by the $\mathrm{NIH}$ (AG12282 to DEB) and by a grant to the Buck Institute from American Bioscience, Inc.

\section{References}

1. Schweichel JU (1972) Electron microscopic studies on the degradation of the apical ridge during the development of limbs in rat embryos. EZ Anat Zntwicklungsgesch 136: 192-203

2. Schweichel JU and Merker HJ (1973) The morphology of various types of cell death in prenatal tissues. Teratology 7: 253-266

3. Schwartz LM (1991) The role of cell death genes during development. BioEssays 13: 389-395

4. Clarke PG (1990) Developmental cell death: morphological diversity and multiple mechanisms. Anat. Embryol. 181: 195-213

5. Lockshin RA and Williams CM (1964) Programmed cell death. II. Endocrine potentiation of the breakdown of the intersegmental muscles of silkmoths. J. Insect Physiol. 10: 643-649

6. Pilar G and Landmesser L (1976) Ultrastructural differences during embryonic cell death in normal and peripherally deprived ciliary ganglia. J. Cell Biol. 68: 339-356

7. Oppenheim RW (1991) Cell death during development of the nervous system. Annu. Rev. Neurosci. 14: 453-501

8. Oppenheim RW (1985) Naturally occurring cell death during neural development. Trends Neurosci. 17: 487-493

9. Cunningham TJ (1982) Naturally occurring neuron death and its regulation by developing neural pathways. Int. Rev. Cytol. 74: 163-186
10. Turmaine M, Raza A, Mahal A, Mangiarini L, Bates GP and Davies SW (2000) Nonapoptotic neurodegeneration in a transgenic mouse model of Huntington's disease. Proc. Natl. Acad. Sci. USA 97: 8093-8097

11. Dal Canto MC and Gurney ME (1994) Development of central nervous system pathology in a murine transgenic model of human amyotrophic lateral sclerosis. Am. J. Pathol. 145: 1271-1279

12. Sperandio S, de Belle I and Bredesen DE (2000) An alternative, nonapoptotic form of programmed cell death. Proc. Natl. Acad. Sci. USA 97: 14376-14381

13. Majno $G$ and Joris I (1995) Apoptosis, oncosis, and necrosis. An overview of cell death (see comments). Am. J. Pathol. 146: 3-15

14. Fadok VA, Voelker DR, Campbell PA, Cohen JJ, Bratton DL and Henson PM (1992) Exposure of phosphatidylserine on the surface of apoptotic lymphocytes triggers specific recognition and removal by macrophages. J. Immunol. 148: 2207-2216

15. Yuan J, Shaham S, Ledoux S, Ellis HM and Horvitz HR (1993) The C. elegans cell death gene ced-3 encodes a protein similar to mammalian interleukin-1 beta-converting enzyme. Cell 75: 641-652

16. Thornberry NA and Lazebnik Y (1998) Caspases: enemies within. Science 281 : 1312-1316

17. Salvesen GS and Dixit VM (1997) Caspases: intracellular signaling by proteolysis. Cell 91: 443-446

18. Yuan J and Yankner BA (1999) Caspase activity sows the seeds of neuronal death. Nat. Cell Biol. 1: E44-E45

19. Rao RV, Castro-Obregon S, Frankowski H, Schuler M, Stoka V, Del Rio G, Bredesen DE and Ellerby HM (2002) Coupling endoplasmic reticulum stress to the cell death program. An Apaf-1-independent intrinsic pathway. J. Biol. Chem. 277: 21836-21842

20. Rao RV, Hermel E, Castro-Obregon S, del Rio G, Ellerby LM, Ellerby HM and Bredesen DE (2001) Coupling endoplasmic reticulum stress to the cell death program. Mechanism of caspase activation. J. Biol. Chem. 276: 33869-33874

21. Rao RV, Peel A, Logvinova A, del Rio G, Hermel E, Yokota T, Goldsmith PC, Ellerby LM, Ellerby HM and Bredesen DE (2002) Coupling endoplasmic reticulum stress to the cell death program: role of the ER chaperone GRP78. FEBS Lett. 514: 122-128

22. Morishima N, Nakanishi K, Takenouchi H, Shibata T and Yasuhiko Y (2002) An endoplasmic reticulum stress-specific caspase cascade in apoptosis. Cytochrome $c$-independent activation of caspase-9 by caspase-12. J. Biol. Chem. 277: 34287-34294

23. Chi S, Kitanaka C, Noguchi K, Mochizuki T, Nagashima Y, Shirouzu M, Fujita H, Yoshida M, Chen W, Asai A, Himeno M, Yokoyama S and Kuchino Y (1999) Oncogenic Ras triggers cell suicide through the activation of a caspase-independent cell death program in human cancer cells. Oncogene 18: 2281-2290

24. Castro-Obregon S, Del Rio G, Chen SF, Swanson RA, Frankowski H, Rao RV, Stoka V, Vesce S, Nicholls DG and Bredesen DE (2002) A ligand-receptor pair that triggers a non-apoptotic form of programmed cell death. Cell Death Differ. 9: $807-817$

25. Mehlen P, Rabizadeh S, Snipas SJ, Assa-Munt N, Salvesen GS and Bredesen DE (1998) The DCC gene product induces apoptosis by a mechanism requiring receptor proteolysis. Nature 395: 801-804

26. Bordeaux MC, Forcet C, Granger L, Corset V, Bidaud C, Billaud M, Bredesen $D E$, Edery $P$ and Mehlen $P(2000)$ The RET proto-oncogene induces apoptosis: a novel mechanism for Hirschsprung disease. EMBO J. 19: 4056-4063

27. Ellerby LM, Hackam AS, Propp SS, Ellerby HM, Rabizadeh S, Cashman NR, Trifiro MA, Pinsky L, Wellington CL, Salvesen GS, Hayden MR and Bredesen DE (1999) Kennedy's disease: caspase cleavage of the androgen receptor is a crucial event in cytotoxicity. J. Neurochem. 72: 185-195

28. Llambi F, Causeret F, Bloch-Gallego $E$ and Mehlen $P$ (2001) Netrin-1 acts as a survival factor via its receptors UNC5H and DCC. EMBO J. 20: 2715-2722

29. Yamamoto K, Altschuler D, Wood E, Horlick K, Jacobs S and Lapetino EG (1992) Association of phosphorylated insulin-like growth factor-I receptor with the SH2 domains of phosphatidylinositol 3-kinase p85. J. Biol. Chem. 267: $11337-11343$

30. Gustavson TA, He W, Craparo A, Schaub CD and O'Neill TJ (1995) Phosphotyrosine-dependent interaction of $\mathrm{SHC}$ and insulin receptor substrate 1 with the NPEY motif of the insulin receptor via a novel non- SH2 domain. Mol. Cell. Biol. 15: 2500-2508

31. O'Connor R, Kauffmann-Zeh A, Liu Y, Lehar S, Evan GI, Baserga R and Blattler WA (1997) Identification of domains of the insulin-like growth factor I 
receptor that are required for protection from apoptosis. Mol. Cell. Biol. 17: 427-435

32. Li S, Resnicoff M and Baserga R (1996) Effect of mutations at serines 1280 1283 on the mitogenic and transforming activities of the insulin-like growth factor I receptor. J. Biol. Chem. 271: 12254-12260

33. Vito P, Pellegrini L, Guiet C and D'Adamio L (1999) Cloning of AIP1, a novel protein that associates with the apoptosis-linked gene ALG-2 in a $\mathrm{Ca}^{2+}$. dependent reaction. J. Biol. Chem. 274: 1533-1540

34. Missotten M, Nichols A, Rieger K and Sadoul R (1999) Alix, a novel mouse protein undergoing calcium-dependent interaction with the apoptosis-linkedgene 2 (ALG-2) protein. Cell Death Differ. 6: 124-129

35. Nickas ME and Yaffe MP (1996) BRO1, a novel gene that interacts with components of the Pkc1p-mitogen-activated protein kinase pathway in Saccharomyces cerevisiae. Mol. Cell. Biol. 16: 2585-2593

36. Negrete-Urtasun S, Denison SH and Arst Jr HN (1997) Characterization of the $\mathrm{pH}$ signal transduction pathway gene palA of Aspergillus nidulans and identification of possible homologs. J. Bacteriol. 179: 1832-1835

37. Hongo A, Yumet G, Resnicoff M, Romano G, O'Connor R and Baserga $\mathrm{A}$ (1998) Inhibition of tumorigenesis and induction of apoptosis in human tumor cells by the stable expression of a myristylated $\mathrm{COOH}$ terminus of the insulinlike growth factor I receptor. Cancer Res. 58: 2477-2484

38. Tennant MK, Thrasher JB, Twomey PA, Drivdahl RH, Birnbaum RS and Plymate SR (1996) Protein and messenger ribonucleic acid (mRNA) for the type 1 insulin-like growth factor (IGF) receptor is decreased and IGF-II mRNA is increased in human prostate carcinoma compared to benign prostate epithelium. J. Clin. Endocrinol. Metab. 81: 3774-3782

39. Plymate SS, Bae VL, Maddison L, Quinn LS and Ware JL (1997) Type-1 insulin-like growth factor receptor reexpression in the malignant phenotype of SV40-T-immortalized human prostate epithelial cells enhances apoptosis. Endocrine 7: 119-124

40. Liu JP, Baker J, Perkins AS, Robertson EJ and Efstratiadis A (1993) Mice carrying null mutations of the genes encoding insulin-like growth factor I (Igf-1) and type 1 IGF receptor (Igf1r). Cell 75: 59-72
41. Chang $L$ and Karin $M$ (2001) Mammalian MAP kinase signalling cascades. Nature 410: $37-40$

42. Mukherjee $P$ and Pasinetti GM (2001) Complement anaphylatoxin C5a neuroprotects through mitogen-activated protein kinase-dependent inhibition of caspase 3. J. Neurochem. 77: 43-49

43. Runden E, Seglen PO, Haug FM, Ottersen OP, Wieloch T, Shamloo M and Laake JH (1998) Regional selective neuronal degeneration after protein phosphatase inhibition in hippocampal slice cultures: evidence for a MAP kinase-dependent mechanism. J. Neurosci. 18: 7296-7305

44. Regan RF, Wang $Y$, Ma X, Chong A and Guo $Y$ (2001) Activation of extracellular signal-regulated kinases potentiates hemin toxicity in astrocyte cultures. J. Neurochem. 79: 545-555

45. Linford NJ, Yang Y, Cook DG and Dorsa DM (2001) Neuronal apoptosis resulting from high doses of the isoflavone genistein: role for calcium and p42/ 44 mitogen-activated protein kinase. J. Pharmacol. Exp. Ther. 299: 67-75

46. Kulich SM and Chu CT (2001) Sustained extracellular signal-regulated kinase activation by 6-hydroxydopamine: implications for Parkinson's disease. J. Neurochem. 77: 1058-1066

47. Allan LA, Morrice N, Brady S, Magee G, Pathak S and Clarke PR (2003) Inhibition of caspase-9 through phosphorylation at Thr 125 by ERK MAPK. Nat. Cell Biol. 5: 647-654

48. Davis RJ (2000) Signal transduction by the JNK group of MAP kinases. Cell 103: 239-252

49. Regan RF, Panter SS, Witz A, Tilly JL and Giffard RG (1995) Ultrastructure of excitotoxic neuronal death in murine cortical culture. Brain Res. 705 : 188-198

50. Chatellard-Causse C, Blot B, Cristina N, Torch S, Missotten M and Sadoul R (2002) Alix (ALG-2-interacting protein X), a protein involved in apoptosis, binds to endophilins and induces cytoplasmic vacuolization. J. Biol. Chem. 277: 29108-29115

51. Koh JY and Choi DW (1987) Quantitative determination of glutamate mediated cortical neuronal injury in cell culture by lactate dehydrogenase efflux assay. J. Neurosci. Methods 20: 83-90 